\title{
The Implementation of Total Quality Management (TQM) On the Higher Educational Sector in Jordan
}

\author{
Dr. Hussien Ahmad Al-Tarawneh \\ Business Administration Department \\ Amman Private University \\ Amman-Jordan
}

Tel: 00962-777466635 drhussientrawneh@yahoo.com

\author{
Mania Moayyad Mubaslat (Corresponding author) \\ Project Manager \\ Jordan Education Initiative \\ Amman-Jordan \\ P.o Box: 329
}

Tel: 00962-777960180 maniamub@yahoo.com

Received: July 01, $2011 \quad$ Accepted: July 14, $2011 \quad$ DOI: 10.5296/ijim.v1i1.771

\begin{abstract}
TQM is a philosophy and system for continuously improving the services and/or products offered to customers. Now that the technologies of transportation and communication have replaced national economic systems with a global economy, nations and businesses that do not practice TQM can become globally non-competitive rather rapidly. This march towards non-competitiveness can be avoided if citizens are helped to become TQM practitioners.

The new economic growth theories have emphasized the role of human capital as the key of economic growth and development. The World Bank's recent study of 190 countries reveals that it is higher education that helps in enriching the quality of manpower. Thus higher education is a basic investment necessary to improve the overall quality of life. The strong linkage between the economy and education was never so clearly visible as now. This paper investigates the application of TQM to educational organizations using Jordanian higher educational sector as a model example. Higher Education is an important sector in Jordan.
\end{abstract}


The government has introduced several laws and constitutions aimed to further develop this sector, improve its ability to compete. However, little work has been done to measure and control quality in this sector. The work will show that the use of TQM can be of great benefit to the Jordanian universities, the paper will also investigate the relation between the application of TQM and the increase in the educational performance and efficiency.

Keywords: Total Quality Management (TQM); Services; educational Sector; Jordan.

\section{Introduction}

The potential benefits of TQM can be applied to school \& colleges. TQM can help a school $\&$ college provide better service to its primary customers-students and employers. The continuous improvement focus of TQM is a fundamental way of fulfilling the accountability requirements common to educational reform. Innovative interactive techniques can be applied to improve the interest of students and teacher. Therefore, the climate for learning is improved. In today's world, organizations are facing the growing challenges from global competition and more sophisticated students in terms of what they want and their changing needs. Most organizations are starting to apply the Japanese methods of production and philosophies in the hope of achieving the required growth in the markets increasing profit. One of the main ideas that came from the Japanese industry is TQM, which means that all workers within a given organization must participate in improving the product or service quality, an activity that was previously the concern of the quality control department faculty. Feigenbaum defines TQM as "An efficient system that aims to achieve total quality through the combined effort of all the faculty within the organization in order to produce a product/service that will meet the needs and expectations of the students' with minimum cost".

Due to the large success of TQM in manufacturing companies, service organizations have started to follow in their footsteps and consider the application of TQM. This was mainly due to the nature service industries in terms of its students' orientation. Thus TQM was applied to universities, hospitals, hotels and education. In order to apply TQM to a service sector it is important to decide on how to evaluate the quality of service. Service can be evaluated according to cost, flexibility, acquirability, totality, and response time. This paper will concentrate on the affect of applying TQM to the services and educational strategies and will use universities in Jordan as a model company (or organization).

\section{TQM and Education}

In a TQM school or college, improvement teams and individuals are constantly working on improving service to customers. The concept of a service being "good enough" is considered inadequate. Thorough understanding of the differences between traditional and TQM schools is best developed in a dynamic seminar, not in a simple written guide. Therefore, this guide is intended to supplement such a seminar. Each of the following elements is very important for fully realizing the potential of TQM in education:

1. Awareness and Commitment for Everyone: EVERY member of a teaching-learning partnership promotes the highest possible quality at each step in the development 
process.

2. A Clear Mission: These standards should emphasize developing students' abilities to solve real-life problems rather than just memorizing subject matter. The latter does not represent quality for either students or employers.

3. A Systems Planning Approach: Traditional education has become excessively compartmentalized. If higher levels of student competence are to be developed, there must be higher levels of system-wide and cross-department PLANNING for instructional improvement in schools and colleges. Such a system approach to learning improvement normally happens only if inter-department planning arranges it.

4. Teaming Replacing Hierarchy: The hierarchical organizations of yesterday need to be replaced by Cross-department teams, coordinating among task. It can promote stronger improvement if they are given a clear mission and strong authority, Supported rather than hampered by supervisors.

5. Enablement AND Empowerment Replacing Fear: Traditional do-it-to-them evaluation systems by themselves generate fear and lack of initiative. Staff members focus on doing whatever is enough to keep the boss happy.

6. Focus on Mastery Learning: In traditional classrooms, teachers often follow this sequence:

1 Plan-------------------> 2 Teach-----------------------> 3 Test

The normal curve that usually results stands as testimony to the fact that many students fail to learn at the highest possible level in this system. The TQM alternative is:

1 Plan--> 2 Teach (DO)--> 3 Check**--> 4 Revised Teaching (ACT)--> 5 Test**

In the "check" step, formative (not-for-grade) testing is used to determine which learning some students have missed. If advisable, the checking and revised teaching can be repeated more than once. Meanwhile students who have mastered the material move to enrichment learning or assist with instruction of those who have not achieved mastery. This system of mastery learning can result in much more complete learning for most students. This improvement in learning is a basic purpose of TQM in the classroom.

7. Development of Student TQM Skills: In addition to using TQM to improve learning in general, every college should specifically equip its students to understand and use TQM. Whether a school staff decides to integrate learning TQM into existing courses or to provide it as a separate course, it is important that students DO and not just study about TQM.

8. A Humanistic and a Brain Compatible Focus in the Learning Environment: Productive learning environment can be improved by six conditions for quality schoolwork: Dr. William Glasser has provided one of the best translations of TQM principles into suggestions for a very productive learning environment. 
a.There must be a warm, supportive learning environment.

b. Students should be asked to do only useful work.

c. Students should be asked to do the best they can do.

d. Students should be asked to evaluate their own work and improve it.

e.Quality work should always feel good.

f. Quality work should never be destructive.

Policies and procedures for the selection of learners are outlined, and learners are given guidance and support.

The focus of Criterion 6 is on learners. Issues of selection of learners, the extent to which their needs are met and what support and guidance they are given need to be explicitly described. Here providers need to be mindful of the following key NQF principles with regard to learners:

- Learner-centerness

- Learner's participation

- Relevance of the programmes to learners

- Recognition of prior learning

- Lifelong learning

\section{Higher Education in Jordan}

Higher education in Jordan developed steadily over the past two decades regarding content, programs, and methods of teaching and learning that affect both quality and quantity. The Higher Education Council, the Accreditation Commission, and the Higher Committee for Scientific Research oversee the programs offered by both private and public institutions and evaluate their effectiveness in implementing higher education's vision, mission, and objectives.

Jordan has achieved noticeable progress and distinction at the pan Arab and regional levels. At present, it is seeking to achieve the same at the international level, especially with respect to development of human resources, despite limited natural and financial resources. For more than half a century, Jordan has witnessed the rise of institutes and universities of higher education which offer solid and advanced learning opportunities. Higher education institutions in Jordan realized early on the importance of empowering individuals, especially the youth, through focusing on the knowledge economy and the use of technology in planning and educational programs. To this end, Jordan has been effecting continuous changes, transformations and developments of the higher education sector with the aim of achieving quality and distinction. Over the years, higher educational institutions in Jordan have attempted to strike a balance between academic and vocational education. 
Future Strategic goals for the Ministry of Higher Education and Scientific Research:

1.Improving Higher Education Sector Management.

2.Improving the quality of Higher Education Environment.

3.Enhancing scientific research quality and the role of higher education institutions.

4.Providing national quality data-bases and periodic studies on the higher education sector and scientific research in accordance with international best practices.

The Ministry has developed a strategy for higher education and scientific research. The main components include admission policies of Jordanian universities, curricula and study plans, developing human resources, university management, quality assurance, and legislation.

Accreditation is the hub of all this. It lays the foundation for quality and excellence. Consequently, it was instituted from the very beginning and assigned to different agencies and bodies, but always impelled by the two objectives, for which purpose a number of by-laws, guidelines and benchmarks were formulated to be observed by the private universities in Jordan as basic requirements for any progress towards quality and excellence. The Accreditation Council, which until recently shouldered this responsibility as a part of the Ministry of Higher Education and Scientific Research was dissolved in June, 2007, and the Higher Education Accreditation Commission was set up in its place by Law (20) for the year 2007. The Commission Council consists of a president, a vice-president, two full-time members, and three part-time members, all of whom are of high academic and administrative qualifications.

According to the enabling law the Commission is administratively and financially independent. It is entrusted with a number of tasks that constitute its mission. The law states that the objective of the Commission is to enhance and guarantee quality in higher education, to encourage universities to be open to and interact with international scientific research institutions and accreditation commissions, and to upgrade higher education in Jordan on the basis of internationally recognized criteria. The Commission Council is empowered to formulate relevant criteria; to audit, evaluate, and accredit institutions of higher education, making sure that they comply with all pertinent regulations; to collect data and do research related to higher education; and to ratify reports by the President and committees and issue relevant research, studies and brochures.

Obviously, the Commission has wider jurisdiction. First, it has a mandate over private and public universities and over all foreign institutions of higher education in Jordan affiliated with Jordanian universities. This means an addition of ten public universities. The total stands now at twenty-six universities. It is not difficult to imagine the amount of extra work and effort to be exerted for this purpose.

Second, the Commission is charged with the establishment and management of The National Testing Center, which will design and conduct all kinds of standardized tests in almost all fields, to be used, among other things, for graduation and admission, and not only an exit test in a limited number of fields, as was formerly the case. A set of by-laws and regulations 
have already been drafted and committees set up to do the job. The plan delineates tests of Arabic for foreign students and aptitude tests as well.

Third, the Commission is working on better ways and means to make sure that the institutions are in full compliance with all its regulations. To this end, the Commission has done a study of these universities on the basis of a number of criteria and come up with a preliminary evaluation and ranking. The step has already had its fruits, urging universities to revise their policies, activate their internal self-assessment plans, and improve their functioning. The system is to be refined and developed to become as accurate as possible. On the other hand, in August 2007, the Commission held a workshop, in which representatives of the universities participated and were apprised of ways to compute capacities, to prepare assessment reports of the university as a whole, of any of its programs and any of its courses, and to administer quality management. To many of those who attended the workshop the experience was eye-opening, enriching their consciousness with new concepts and practices. More, of course, needs to be done along the same lines. For this same purpose, the Commission plans to organize more workshops of similar kind to train assessors, who are able to audit, evaluate, and prepare self-assessment reports; to bring total quality management into the university academic environment and to make it one of the major concerns of both staff and faculty; and finally to develop the culture of excellence by both knowledge and practice. To bring all this to full fruition, the Commission intends to make it imperative that all institutions set up quality and internal audit departments for purposes of accreditation on national and international bases. The National Testing Center, and others to contribute to the Commission's efforts to upgrade existing accreditation criteria and formulate new ones

\section{TQM Model}

In order to achieve the goals and aims of the study, a model was adopted and adapted that reflects the relation between the dependent and independent variables. This model can be seen in Figure 1.

The model shows the interaction between the elements of TQM in order to achieve a continuous improvement in the outcomes and operation of the target organization, thus achieving students' satisfaction. The model structure is made of three building blocks:

Requirements: These are the basic requirements and building blocks for the initial implementation of TQM. These are: Approval of the philosophy, commitment toward the philosophy and availability of critical information needed for the implementation and measurement of performance.

Actions: These are the activities needed for the implementation of the philosophy in the organization. These include: training of faculty in the aspects of TQM and the meaning of the philosophy, participation and involvement of the upper management in the implementation phase and structural organizational change needed for implementation in terms of responsibilities, departments and management levels.

Results: These are the results from implementing TQM in an educational organization, which include students' satisfaction and the educational development. 


\section{Macrothink}

Embedded in the model is the continuous improvement concept. This is because universities that intend to apply the model will have to measure their performance and compare it to the competitor's performance. This will allow the universities to get a feed back about the level of required improvement and what must be done to achieve better results.

Figure 1. The proposed TQM model for the study

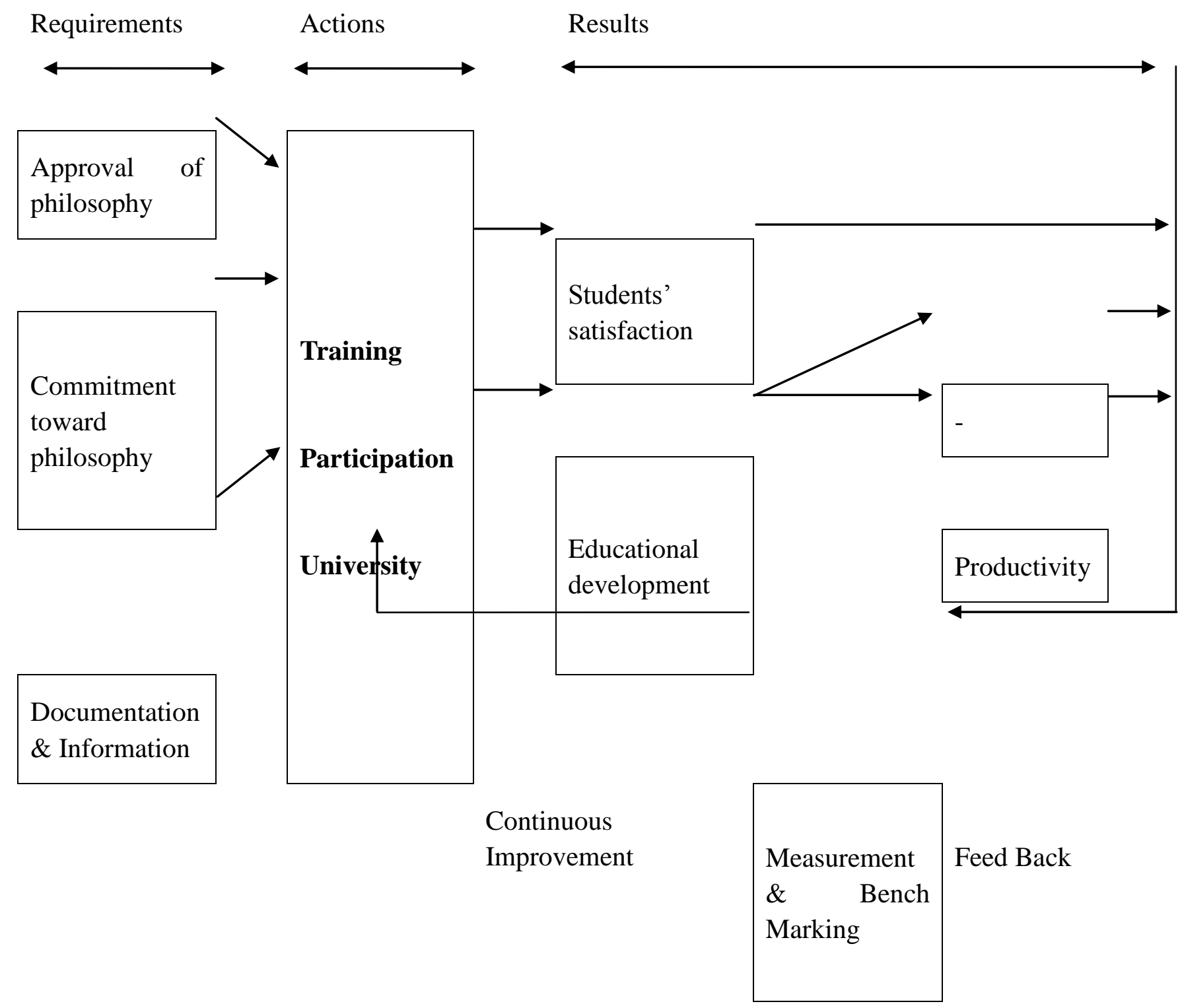

\section{Research Methodology}

In order to understand the current state of application of TQM in the higher education sector in Jordan based on the model shown in Figure 1, a survey was conducted to measure each of the level of readiness and implementation of the three basic building blocks. The results from 
the implementation of TQM in universities (students' satisfaction and educational development) were measured as follows:

Students' satisfaction was measured via a questionnaire, which evaluated their level of satisfaction from the services rendered by the university.

The requirements and actions needed for the implementation of the TQM philosophy were measured by a second questionnaire answered by the faculty and management personnel. This questionnaire investigated the requirements of TQM (approval of philosophy, commitment toward philosophy and documentation and information) and actions should be taken to achieve TQM implementation through questions related to TQM principles.

\subsection{Study Sample}

The study sample was divided into two groups: faculty and students.

For the faculty, (200) Questionnaires were distributed on (8) Jordanian private and public universities that were selected randomly and according to universities management's cooperation with researchers Two of these universities are ISO certified, while the other six are committed to TQM principles according to top management memorandums and strategic plans. The questionnaires were distributed to the faculty of these universities in different departments and different levels all within different governorates in Jordan (120) Questionnaires were retrieved.

For the students group, (600) Questionnaires were distributed on Jordanian universities students that were selected randomly from the universities under study in different specializations. (425) Questionnaires were retrieved.

\section{Results and Analysis}

The 5-Likert scale has been used in the questionnaire with the following values: highly agree (5), agree (4), approximately agree (3), disagree (2), and completely disagree (1). The mean and the standard deviation of the different questions were calculated. It was considered that the student or the faculty agree on a given statement when the mean is (3.5) or more. A mean below this value, indicate a negative response. For the purpose of testing hypotheses, the joint mean for all statements was calculated to be considered as the factor of analysis (reference), while the individual mean of single questions representing for the same hypothesis was calculated to be compared with the reference using One Way Analysis of Variance (ANOVA).

The study revealed that there is a general approval of the study sample that the level of TQM implementation is moderate. This indicates that there is a high awareness from the top management to adapt the TQM concept. The attitudes of the respondents regarding the principles of the TQM were within a high mean. The results showed that there is nearly equal adaptation from the universities to all principles of TQM. While in reality there is little focus on students' needs and complaints regarding to students viewpoint.

The study revealed that there is a high rational relationship between all TQM principles and the organization performance in Jordanian universities measured in productivity and 
profitability. The evaluation of Jordanian universities students to the provided services quality level was positive although the general feeling of students was not satisfied.

On the student's side, the study showed that student's evaluations regarding the provided educational services quality differs, and this gives to the management an indication of the need of giving high priority to develop quality approaches. The modern techniques equipments(teaching pedagogies) available in the university have nearly the highest importance in students' evaluation, so the universities should give it most priority in their development process. There is a relationship between the evaluation of Jordanian universities students to the actual provided services quality level and the number of dealing frequency with the university. The evaluation of Jordanian universities students to the actual provided services quality level differ dependent on dealing with other faculties. This give a true student's evaluation to actual services quality level provided by the evaluated universities compared to other faculties they deal with.

\section{Conclusions}

TQM is a general management philosophy and set of tools which allow an institution to pursue a definition of quality and a means of attaining quality, with quality being a continuous improvement ascertained by customers' contentment with the services they receive. TQM can be applied to higher education, but it must be modified to fully recognize some unique aspects of education viz education is a service industry with no visible, tangible "product". Benefits of TQM include heightened employee morale, better teamwork among departments, bridging faculty-staff functions, increased quality from customer viewpoint and continuous development of everyone who is part of higher education institution.

\section{References}

Ali. Murad . and Shastri. 2Rajesh,2010.Implementation of Total Quality Management in Higher Education, Asian Journal of Business Management 2(1):

Durlabhji, S.G. and M.R. Fusilier, 1999. The empowered classroom: Applying TQM to college teaching, Manag. Serv. Qual., 9(2): 110-115.

Osseo-Asare E.A.Jr. and D. Longbottom, 2002. The need for education and training in the use of the EFQM model for quality management in UK higher education injstitutions. Qual. Assur. Edu., 10(1): 26-36.

Fullan, M., 1993. Change Forces, Falmer, London.

Gaither, N., 1996. Production and Operations Management, Duxbury Press, Cincinnati, OH, pp: 7.

Glasser, William, 1998. The Quality School Teacher: A Companion Volume to The Quality School.

Gregory, M., 1996. Developing effective college leadership for the management of educational change. Leadership Org. Dev. J., 17(4): 46-51. 


\section{Macrothink}

International Journal of Industrial Marketing

ISSN 2162-3066

2011, Vol. 1, No. 1

Harris, R.W., 1994. Alien or Ally? TQM,Academic Quality and the New Public Management. Quality Assurance. Education., 2(3): 33-39.

Iven, H., 1995. Dearing's dilemma. Education, 9 June, Vol: 14.

Koch, J.V., 2003. TQM; why is its impact in higher education so small?. The TQM Magazine, 15(5): 325-333.

Lawrence, J.J. and M.A. McCollough, 2001. A conceptual framework for guaranteeing higher education. Qual. Assur. Edu., 9(3): 139-152.

Marsh, D.T., 1992. Leadership and its functions in further and higher education. Mendip Paper. The Staff College, Bristol.

Michael, R.K., et al., 1997. A comprehensive model for implementing total quality management in higher education. Benchmark. Qual. Manage. Technol., 4(2): 104-120.

Owlia, M.S., and E.M. Aspinwall, 1997. TQM in higher education-a review. International J. Qual. Rel.

Manage., 14(5): 527-543. Sangeeta, et al., 2004. Conceptualising total quality management in higher education. The TQM Magazine, 16(2): 145-159.

Roffe, I.M., 1998. Conceptual problems of continuous quality improvement and innovation in higher education. Qual. Assur. Higher Edu., 6(2): 74-82.

Salman D. Al-Shobaki \& Others,2010. The Implementation of Total Quality Management (TQM) for The Banking Sector in Jordan.JJMIE

Srivanci, M.B., 2004. Critical issues for TQM implementation in higher education. The TQM Magazine, 16(6): 382-386.

Witcher, B.J., 1990, Total Marketing: Total Quality and Marketing Concept. The Quarterly Review of Marketing Winter. 